\title{
CONF-850657--2
}

\section{DETERMINATION OF THORIUNi AND URANIUM AT THE NANOGRAM PER GRAM LEVEL IN SEMICONDUCTOR POTTING PLASTICS}

BY NEUTRON ACTIVATION ANALYSIS*

F. F. Dyer, J. F. Emery, and L. C. Bate

Anaiytical Chemistry Division, Oak Ridge National Laboratory Oak Ridge, Tennessee 37831 (USA)

\section{DISCLAIMER}

This report was prepared as an account of work sponsored by an agency of the United States Government. Neither the United States Government nor any agency thereof, nor any of their employees, makes any warranty, express or implied, or assumes any legal liability or responsibility for the accuracy, completeness, or usefuiness of any information, apparatus, product, or process disclosed, or repiesents that its use would not infringe privately owned rights. Reference herein to any specific conmercial product, process, or service by trade name, trademark, manufacturer, or otherwise does not necessarily constitute or imply its endorsement, recommendation, or favoring by the United States Government or any agency thereof. The views and opinions of authors ixpressed h=rein do not necessarily state or reflect those of the United States Government or any agency thereof.

ॠResearch sponsored by office of Energy Research, U. S. Department of Energy, under contract DE-AC05-840R21400 with Martin Marietta Energy Systems, Inc. 


\title{
DETERMINATION OF THORIUM AND URANIUM AT THE NANOGRAM PER GRAM LEVEL IN SEMICONDLITIOR POTTING PLASTICS \\ BY NEUTRON ACTIVATION ANALLYSIS
}

F. F. Dyer, J. F. Emery, und L. C. Bate*

Analytical Chemistry Division, Nak Ridge National Laboratory

Oak Ridge, Ternessee 37831 (USA)

\begin{abstract}
A method was developed to determine thorium and uranium in semiconductor potting plastics. The method is based on neutron activation and subsequent radiochemical separation to isolate and permit measurement of the induced $233 \mathrm{~Pa}$ and ${ }^{239} \mathrm{~Np}$. These plastics typically contain macro amounts of siicon, bromine and antimony and nanogram per gram amounts of thorium and uranium. The radiochemical method provides the necessary sensitivity and makes it possible to easily attain adequate decontamination of the tiny amounts of $233 \mathrm{~Pa}$ and ${ }^{239} \mathrm{~Np}$ from the high levels of radioactive bromine and antimony.
\end{abstract}




\section{Introduction}

This report descrides a method that was developed to determine thorium and uranium in plastics in which semiconductor memories are mounted. The method is based on neutron activation to form $233 \mathrm{~Pa}$ and $239_{\mathrm{Np}}$ followed by radiochemica? separations to isolate and permit measurement of these nuclides. From the measured decay rates of $233 \mathrm{~Pa}$ and $239 \mathrm{~Np}$, the concentrations of thorium and uranium were estimated by the method of absolute activation analysis as was done previously in a study of $T h$ and $I J$ in computer memory materials. 1 Other analytical disciplines such as mass spectrometry, fluorometry, laser induced fluorescence and ionization and combinations of these methodologies provide adequate semsitivity to measure either one or both of these nuclides at the ppb level.2 At the present time however, these other analytical techniques would require extensive sf.parations of thorium and uranium with considerable risk of contam natiun and, except under the most strictly controlled laboratory cond tions, would not provide the reliability inherent in neutron activation analysis.

During the past 4-5 years we have been asked occassionally by several comiercial sources to make these measurements, and the oresent method represents what has evolveu from those efforts. Interest in such analyses apparently stems from a concern for a possible contribu.. tion of alpha emitters in the plastics to the so-called "soft error" effect even though barrier layers may be used to isolate memories from their mounts. ${ }^{3}$ Potting materials analyzed in this study contained thorium and uranium in the nanogram per gram range and macro amounts of silica, bromine, and antimony. The radiochemical separations served mainly to isolate the small quantities of induced $233 \mathrm{~Pa}$ and
$239 \mathrm{~Np}$ from the high levels of $82 \mathrm{Er}, 122 \mathrm{Sb}$, and $124 \mathrm{Sb}$ that were formed.

\section{Experimental}

Irradiations were made in the pneumatic tube system of the High Flux Isotope Reactor (HFIR) described previously in Ref. 1. The rabbit loading station is located in a hot cell fitted with remote manipulators and shielded entry ports through which materials can be entered or removed when high radiation levels exist inside. The hot cell also has a large hinged door containing a lead glass window: When the radiation level inside the cell is low, the door can be opened and the cell used in the manner of a chemical fume hood. The wails of the cell are made of $12.7 \mathrm{~cm}$ low-carbon cast steel. The radioactivity generated in samples irradiated in this study was detectable but not hazardous outside the cell. Rabbits are stopped on air columns at both ends of the flight tube thus permitting irradiation of brittle and fragile materials including rabbits made of graphite. All samples in this study were irradiated in high purity graphite rabbits fabricated by Union Poco from Grade AXF-5Q1 graphite purified to $5 \mathrm{ppm}$ or less. These rabbits have proved to be remarkably resistant to breakage. After approximately 200 irradiations no rabbit has broken and no physical deterioration, except slight erosion, is apparent. In addition, the trace element content is so low that almost no long-lived radioactivity builds up, and unless contaminated internally rabbits can be reused many times. These rabbits were observed to contain about $0.5 \mathrm{ppb}$ uranium and 0.3 ppb thorium. 
During this study the thermal neutron flux was nominally $4.5 \mathrm{x}$ 1014, and most irradiations were made for one hour yielding a thermal neutron fluence if $1.6 \times 10^{18}$. For such exposures 1 rig of $238 \mathrm{U}$ yields $2140 \mathrm{~Bq}$ of $239 \mathrm{~Np}$ and $1 \mathrm{ng}$ of $\mathrm{Th}$ yields $\sim 12 \mathrm{~Bq}$ of $253 \mathrm{pa}$. Samples contained about seventy percent silica, one percent bromine and two percent antimony. Samples weighing about 0.5 gram were normally used and thus contained about 15 millicuries of both $92 \mathrm{Br}$ and $122 \mathrm{Sb}$ as well as $1 \mathrm{mCi}$ of $124 \mathrm{Sb}$ following irradiation. Because of this relatively high level of radioactivity, it was necessary to carry out remotely in the hot cell the first few steps of the procedure.

After irradiation, samples were removed from the rabbits, placed in alumina boats and inserted in a quartz tube furnace where they were burned in air overnight at $500^{\circ} \mathrm{C}$. Experiments with unirradiated samples tagged with ${ }^{233 \mathrm{~Pa}}$ and ${ }^{239} \mathrm{~Np}$ showed that about 3 percent of these nuclides were lost from the samples during the overnight combustion. Such a loss does not appear to be inconsistant with tabulated melting and boiling points of these elements. ${ }^{4}$ During combustion, samples did not appreciably change size or shape but merely changed from a dari grey to the white color of silica. The low flowrate air stream that was conducted through the furnace tube was exhausted through two hasic scrubbers to remove radioactive gasses that evolved from the sampies. All of the bromine and perhaps 10-20 percent of the antimony were removed from samples during combustion and were mostly deposited on the cold quartz and plastic tubing leading to the scrubbers. After combustion, samples were placed in $25 \mathrm{ml}$ platinum ciucibles and about $2 \mathrm{ml}$ of concentrated sulfuric acid was added. While being warmed on a hot plate, concentrated (40\%) HF was added incrementa)ly (a few drops at a time) to dissolve the silica and evolve $\mathrm{SiF}_{4}$. After all the slicon had apparently evolved, the sides of the crucible were washed down with HF and the temperature was brought slowly to about $250^{\circ} \mathrm{C}$ and left at that temperature for about one hour. The temperature was lowered to about $125^{\circ} \mathrm{O}$, and concentrated $\mathrm{HCl}$ was added and evaporated 2-3 times to expel the HF. The solution was transferred to a centrifuge tube using $2 \mathrm{~N} \mathrm{HCl}$ to wash the crucible and effect the transfer. Enough 1-2 N HCl was added to obtain a sample of about 10 $\mathrm{ml}$. After expulsion of the $\mathrm{SiF}_{4}$ was complete, a tiny amount of precipitate was visible in the platinum crucible, and after being diluted to $10 \mathrm{sl}$, the solution contained a faint cloudiness with perhaps a tiny precipitate in the centrifuge tube. Using ash from unirradiated plastic tagged with $233 \mathrm{~Pa}$ and $239 \mathrm{~Np}$, it was found that if the solution is centrifuged sufficiently (about 10-20 minutes) to remove the cloudiness, the $233 \mathrm{pa}$ is quantitatively coprecipitated and all the $239 \mathrm{~Np}$ is left in solution. This separation of protactinium and neptunium was made a part of the overall procedure. The solution was decanted and analyzed for $239 \mathrm{~Np}$, and the precipitate analyzed for $233 \mathrm{pa}$. The few attempts made to characterize the precipitate are described in the Discussion Section.

Several different methods to isolate the neptunium from the antimony were investigated. These efforts are described in the Discussion Section. The difficulty with many methods in effecting the separation is due to the tendency of antimony to not be cleanly transferred in any particular separation step. It was found that a very high degree of separation could be obtained by extracting $\mathrm{Np}$ (IV) into xylene 
containing $0.5 \mathrm{M}$ thenoyltrifluoroacetone (TTA). The procedure used was an adaptation of those of Moore and Dorsett presented in the Monograph: Radiochemistry of Neptunium. ${ }^{5}$ A few milligrams of La(NO) 3 was added to the solution, and with stirring $6 \mathrm{~N} \mathrm{KOH}$ was added until the solution was strongly basic and La(OH/3 precipitated. Neptunium hydroxida quantitatively coprecipitated along with some antimony. The solution was centrifuged, the supernate discarded, the ppt dissolved in $1 \mathrm{NHCl}$ and ferrous sulfamate was added to insure that neptunium is reduced to $\mathrm{Np}$ (IV). The solution was transferred to a plastic centrifuge tube and $\mathrm{HF}$ was added to precipitate $\mathrm{LaF}_{3}$ and $\mathrm{NpF}_{4}$. The precipitate was isolated, dissolyed in a few $\mathrm{ml}$ of a solution that was $0.5 \mathrm{~N}$ in $\mathrm{HNO}_{3}$ and $\mathrm{I} \mathrm{M}$ in $\mathrm{Al}\left(\mathrm{NO}_{3}\right)_{3}$ and the neptunium was extracted into xylene that was $0.5 \mathrm{M}$ in TTA. At this point the ${ }^{239} \mathrm{~Np}$ was normally suffi-iently free of radio antimony to be measured by Ge(Li) gamma spectrometry. In some instances it may be necessary to strip the $\mathrm{Np}$ from the organic into $10 \mathrm{M}$ nitric, as described in Ref. 5, and either recycle the extraction or coprecipitate with $\mathrm{La}(\mathrm{OH})_{3}$.

The precipita:e containing the $233 \mathrm{~Pa}$ that was isolated following evolution of $\mathrm{SiF}_{4}$ had ou much radioactive antimony to permit direct ineasurement $\sigma_{i}$ the protactinium. The isolation of the $\mathrm{Pa}$ from the Sb isotopes was effected using methods suggested in the Monograph by Kirby: "The Radiochemistry of Protactinium".6 The precipitate was dispersed in a few $\mathrm{ml}$ of a solution that was $6 \mathrm{~N}$ in both sulfuric and hydrofiuoric acids and the mixture was returned to the platinum crucible. It was found that if the mixture was heated to about $100-150^{\circ} \mathrm{C}$ for a short period, the $233 \mathrm{~Pa}$ was made soluble even though the precipitate (or nost of it) was not dissolved. After the protactinium was dissolved, the mixture was transferred to a centrifuge tube, centrifuged, and the supernate, which now contained the $233 \mathrm{~Pa}$, was returned to the platinum crucible. The solution was heated with the addition of $\mathrm{HCl}$ to expel $\mathrm{HF}$ and make it possible to form precipitates of protactinium. A few milligrams of $\mathrm{La}\left(\mathrm{NO}_{3}\right)_{3}$ was adcied and the protactinium was coprecipitated with $\mathrm{La}(\mathrm{OH})_{3}$. The precipitate was then dissoived in $1 \mathrm{~N}$ nitric acid and the Pa-233 extracted into xylene contıining TTA and measured.

\section{Discussion}

The complete elimination of radioactive bromine from the sample in the dry combustion process is one of the most useful aspects of this method. In earlier attempts to analjze potting materials we made use of wet oxidation by allowing a refluxing mixture of fuming nitric and sulfuric acids to oxidize and dissolve samiples. After oxidation appeared to be complete, distillation was carried out using fuming nitric and hydrobromic acids to distill radioactive bromine and antimony. This technique was slow, nazardous, and largely ineffective for both elements. After dry oxidation was adopted, and evolution of bromine was found to be so effective, attempts were made to similarly evolve antimony as the chloride. After oxiciation of the organic portion of the sample was complete, the air sweep gas was bubbled through concentrated $\mathrm{HCl}$. Argon, substituted for air , was al so bubbled through $\mathrm{HCl}$ and conducted over the sample ash. Some additional release 
of antimony was observed but not enough to be of practical value. The use of argon (or nitrogen) containing chlorine or bromine might result in significant additional reipase, but such sweep gases were not investigated. It seems likely that halide containing sweep gases would increase the volatility and loss of $\mathrm{Pa}$ and $\mathrm{Np}$, but the method would be simplified significantly if all the antimony could be volatilized without appreciable losses of protactinium and neptunium.

The use of a nitric acid medium for the final solvent extraction of TTA chelates of $\mathrm{Np}$ and $\mathrm{Pa}$ is another useful aspect of the procedure. Extractions from nitric acid were found to provide much higher decontaminations from antinony than extractions from hydrochloric acid. Such behavior is probably due to the well known tendency of antimony chloride complexes to extract. The method used by Grimanis to extract SbBr3 from sulfuric acid into benzene might well be used as the basis of separating high levels of antimony from sinall amounts of protactinium and neptunium, but this possibility was not studied.

On several occasions in the development of this method the use of anionic ion exchange to isolate $\mathrm{Pa}$ and $\mathrm{Np}$ from antimony was attempted. Both $\mathrm{HCl}$ and $\mathrm{HNO}_{3}$ media were tried. Although this procedure was not evaluated thoroughly, the well known tendency of antimony to not cleanly elute from anionic resins probably limits the usefulness of the technique where antimony activity is present in such relatively large amounts.

The precipitate on which protactinium was separated from neptunium after $\mathrm{SiF}_{4}$ was evolved was never charcterized. The precipitate was present after every sample was processed by this procedure. Initially it was felt that dissolution should be effected because of the possibility that some portion of the $233 \mathrm{~Pa}$ and/or $239 \mathrm{~Np}$ might be incorporated in the precipitate that could not be recovered. A serious effort to dissolve the precipitate was therefore undertaken and the precipitate was subjected to a number of reagents over a wide range of temperatures. Various concentrations of $\mathrm{HCl}$ and $\mathrm{HNO}_{3}$ were used from ambient to boiling temperatures, as were Aquia Regia, and concentrated sulfuric acid from ambient to near boiling temperatures. Molten $\mathrm{KOH}$, ammonium bisulfate, and ammonium persulfate were tried as agents to make the material soluble in water and/or acids. Although sequential treatments with combinations of several of these reagents appeared to decrease the amount of the precipitate the cloudiness that it produced in solutions was always present. Twice, nonradioactive portions of the material were isolated and analyzet by electron excited EDAX. Macro amounts of elements observed were Al, Ca, Sb, Si, $\mathrm{Zn}$, and $\mathrm{Fe}$. No empirical formula could, however, be assigned to the material. The effort to dissolve and characterize the material was discontinued after the tes: described in the Experimental Section, showed how easily $233 \mathrm{~Pa}$ could be sorbed and removed from the material. It seems highly likely that because of the small size of the particles of which the precipitate is composed that the $233 \mathrm{~Pa}$ that is indigenous to the irradiated potting material would behave similarly, and no bias to analysis of either $233 \mathrm{~Pa}$ or $239 \mathrm{~Np}$ is believed to occur.

As indicated in the Experimental Section, losses of protactinium and neptunium tracers during the combustion were only a few percent, and recovery of the tracers left after combustion were quantitative. Losses of both tracers in coprecipitations with $\mathrm{La}(\mathrm{OH})_{3}$ and $239_{\mathrm{Np}}$ with $\mathrm{LaF}_{3}$ were tested and found to be essentially quantitative. Extractions $n_{\text {ith }} \Pi A$ are well known to be near quantitative under the 
conditions used in this procedure. It is therefore believed that the chemical yield for both protactinium and neptunium are greater than 90 percent. If only uranium measurement is desired for a sample, the cominon practice of tracing the yield with $237 \mathrm{~Np}$ could be employed although the tracer added to potting material would not strictly correspond chemically to that formed in the material during the irradiation. To trace the yield of $233 \mathrm{~Pa}, 231 \mathrm{~Pa}$ might be usef, but the chemical similarity question also applies. Additionally, ${ }^{231} \mathrm{~Pa}$ is a garma emitter and might interfere with the measurement if the $233 \mathrm{~Pa}$ to $231 \mathrm{~Pa}$ ratio were $10 \mathrm{w}$. The best way to test yield would be to analyze a potting material containing a known concentration of thorium and uranium.

The authors wish to thank C. S. MacDougall for carrying out certain electron excited energy dispersive $X$-ray analyses.

\section{References}

1. F. F. DYER, J. F. EMERY, K. J. NORTHCUTT, R. M. SCOTT, J. Radioana1. Chem., 72, 1-2(1982)53-67.

2. F. F. DYER, M. P. MAY, R. L. WALKER, T. G. SCOTT, G. M. CATON, J. R. STOKELY, Evaluation of Isotope Dilution Mass Spectrometry for Bioassay Measurement of Uranium, Plutonium, and Thorium in Urine, NUREG/Cr-3950, ORNL/TM 9006 (1984).

3. J. MCLEOD, Electronic Design, 28 (1980)36.

4. Langs Handbook of Chemistry, J. A. DEAN (Ed.), 12 ed. (1979).

5. G. A. BURNEY, R. M. HARBOUR, Radiochemistry of Neptunium, NAS-NS-3060 (1974).

6. H. W. KIRBY, Radiochemistry of Protactinium, NAS-NS-3016 (1959).

7. A. P. GRIMANIS, Anal. Chim. Acta, 41(1) (1968) 15-21.

8. E. P. MIGNONSIN, J. Radioanal. Chem., 19 (1974) 33-34. 